\title{
Contract Delay What Is It and How Are We Performing?
}

David Finnie (Otago Polytechnic, New Zealand)

\begin{abstract}
This paper examines the management of contract delays in the construction industry as currently practised, and suggests some best practice alternative methods. Research results about the level of contractor's time management skills were analysed to determine the related impact on their ability to manage contract delays. A comparison was made between three conditions of contracts used in New Zealand to determine how delay management should be managed with a discussion about how the different contract conditions distribute risk among the parties. Recommendations were made to improve contract conditions, up-skill industry practitioners and ensure student graduates have adequate delay management skills.
\end{abstract}

\section{Introduction}

One of the main measures of a construction project's success is time (Pino, 2010). The responsibility for finishing a project on time is a complex issue. Contractors must ensure that the building is constructed within the contractual completion date, or risk the imposition of financial penalties. If the Principle or their Agent are the cause of the delay however, the completion date may be extended to compensate the Contractor. The Principal and their Agent must therefore ensure that they provide the Contractor with information in a timely manner, to avoid causing delays. Contract conditions may also contain provisions for the Contactor to be awarded extensions of time (EOT) for other types of specified delays, such as inclement weather.

Effective project time management is highly dependent on the Contractor, and can be adversely affected in a number of ways. Over recent decades the use of technology such as computer software has changed the way that programme schedules are developed and analysed, with a massive increase in sophistication. The software creates complex links between schedule tasks, and can identify the longest sequence of interdependent tasks, the critical path, which is the most critical task sequence for successful time management. The critical path may then be compared against paths which contain float to help determine the impact of a delay on the overall completion date. However, these new systems rely on the competency of the practitioners who operate them.

Research has been carried out which found a significant lack of Contractor skill around time management. Insufficient skill in managing project time will also impair a Contractor's ability to identify and claim for contract delays. The contract conditions themselves may also impact on the efficiency of processing delays, through the designated method for distributing risks among parties, and through the lack of clarity in the way that the contract is written.

This widespread shortfall of industry knowledge would indicate both a need for existing practitioners to be up-skilled, and for educational institutions to ensure that their student graduates have sufficient delay management skills. 


\section{How Well Does Industry Manage Contract Delays?}

\section{Submission of Extension of Time Claims (EOT)}

The effective submission of EOT claims begins with effective time management. Time management begins with the definition and acceptance of a baseline programme. This programme must include the logical sequence of activities which form the as-planned critical path.

However, the original baseline programme is seldom followed accurately. Reasons for this include the difficulty of predicting every future event accurately at the time the baseline programme is written, and the possibility that the programme writer may be quite isolated from the actual construction work and out of touch with actual events (Pickavance, 2001). New ways of doing things may also be found during the construction phase. A further complicating factor is the complexity of the modern schedule produced with computer software to logically sequence tasks. The typical modern schedule may contain between 1,000 and 10,000 components, including a) tasks, b) at least three tasks relationship for every task, and c) associated resource and costs constraints (Barry, 2009). Furthermore, over the last few decades the construction industry has experienced an increasing demand for design and build, guaranteed maximum price and engineer procure and construct contracts. These require the Contractor to accept greater risk, and to develop more efficient and technologically complex solutions, all within shorter time scales and tighter financial constraints (Pickavance, 2009). Farrow's 2001 comment, that "delay analysis today is more involved, more analytical, more forensic and more challenging feature of construction law than it was ten years ago" (p. 3), is even more true today.

Following the agreement of the baseline programme, it needs to be updated regularly throughout the construction period to reflect changes in the actual sequence and performance of construction and to accommodate any changes in the scope of works variations which may be instructed by the Principal. Accordingly, regular notes should be made, for instance in a daily site diary, to record progress, the logic of events, and any circumstances affecting the construction. McDonough (2006) and Nash (2006) identified that communications between parties should be recorded and preserved. NZ Master Builders SCC 10.4 provides that a Subcontractor who delays the Contract Works may be liable for a portion, or all, of any liquidated damages "as the Contractor may suffer as a result of the Subcontractor's default". However, it will be difficult for the Head Contractor to determine which of their Subcontractors caused the delay if they have failed to kept adequate records. This challenge may be further complicated by the many changes which can occur to the Contractor's programme over the duration of the project, due to such things as contract variations and the re-aligning of resources to maximise efficiency. Importantly, Clause 10.1.2 states that any "Revisions to the Contractor's current construction programme, or to the times when the Subcontractor is to carry out and complete any part of the Subcontract Works, must be communicated to the Subcontractor in a timely manner".

So what is the level of understanding and conduct regarding time management in today's construction industry? In 2008 the Chartered Institute of Building (CIOB) conducted a survey among 400 companies to which they received 73 responses. Their thesis underpinning the research was that little had changed in time management since the development of the bar chart, nearly 100 years ago (Pickavance, 2009). From their research, they uncovered a number of interesting facts:

a) Repetitive, low-rise projects had a greater chance of success, as they could generally get by with less sophisticated programme management processes.

b) The quality of time management on complex construction projects was found to be poor.

c) Time control, if it existed, was left to the Contractor, with little collaboration between project participants.

d) Programmes were often used solely as a political tool to protect companies and managers against blame for delays rather than being used to monitor and review progress and to minimise the consequence of delays. 
e) Only one fifth of respondents said they would voluntarily report a delay even if contractually required to do so. Nearly half felt that they would not report the delay because they thought they would be able to remedy it. A third did not want to upset the Principal, and a tenth admitted they may be able to blame someone else.

f) Interestingly, $95 \%$ of respondents thought that education and training in the management of time was unsatisfactory.

These finding are of great concern when compared with the actual requirements of construction contracts for managing contractual delay. For example if we look at NZIA SCC requirements of Contractors when submitting an EOT claim, they are that the Contractor must apply in writing and:

\section{NZIA SCC Clause 11.5.2}

a) do so within 5 working days, or as soon as practicable, after the delay begins;

b) state in sufficient detail the grounds for the extension, including the cause of the delay relied on;

c) specify the number of working days claimed.

NZIA SCC Clause 11.6 "must take reasonable steps to avoid delays and minimize the effects of these delays"

A Contractor cannot possibly hope to submit an extension of time claim within the required time frame if, firstly, they have not been monitoring progress and updating their programme regularly, and secondly, if they are reluctant to do so for any of the reasons given above. Moreover if the Contractor's programme is not constructed properly with sequencing between tasks to identify the critical path, it will be very difficult to calculate the number of working days claimed.

\section{Evaluation Time Delay}

Delay analysis is the "investigation into the issue of what has caused a project to run late." (Farrow, 2001, p. 4). It can be a challenging process involving many complicating factors, and a range of different evaluation techniques which may be adopted. Generally, the process involves identifying which delays have occurred to the critical path and calculating the amount of delay caused. When analysing delays; firstly the incident and effect of the delay should be identified then secondly the cause should be established (Barry, 2009). McDonough (2006, p. 6), identified three key questions to be answered in the investigation and analysis of delay claims: Who and what delayed the project? Was the delay critical to completion? And who is responsible for the additional costs under the contact?

The analyst needs to be aware of the different evaluation techniques and be able to select the best technique to the case at hand. Barry (2009) identified the five main types of delay evaluation techniques:

1) The impacted as-planned analysis method: In this prospective (future orientated) analysis method, a new as-planned programme is compared to the original base-line programme to determine the effect of the delay on completion. Importantly, it does not determine the cause of the delaying event. Barry (2009) recommended that this method only be used where delays occur at the outset of the project or where a contract specifically requires its use.

2) The Time impact analysis method: Recommended by the SCL Delay and Disruption Protocol (The Society of Construction Law, October (2002) sourced from Barry (2009)) and is widely used. It is both a dynamic (involves computer aided schedule calculations) and prospective method. One advantage of this method is that it takes account of the timing and effect of the delay. In order to be effective, this method requires programmes to be well detailed and up to date. In this method the programme is updated to the point at

Finnie, D (2012) 'Contract delay what is it and how are we performing?', Australasian Journal of Construction Economics and Building, 12 (1) 83-91 
which a delay occurs then the delay is added and a new completion date is established in recognition of the actual progress up to the delay and the delay itself.

3) The Collapsed as-built or "but-for" analysis method: Being a retrospective (past orientated) method, it performs well when all the information is fully available. However, being dynamic this method requires a network schedule. The process involves retrospectively reinstating the logical relationship of links to the as-built schedule at the end of the project (the as-built schedule is the fully updated baseline schedule with the links overwritten as part of the updating process). However, it can be a very complicated process to restore all of the links, especially to a complicated project. Once the links have been restored a known delay event may be removed to determine what he schedule would have been if the delay had not occurred. This process does not account for every possible sequence of the events if the delay had not occurred and so this method must be accepted as hypothetical only. It is best used in a project where either all tasks are linear or the delay occurs near the end of the project.

4) Snapshot windows/ time slice analysis method: Also retrospective and dynamic, this method relies heavily on a network baseline or host schedule and regularly updated, asbuilt data. The baseline schedule is regularly updated to provide various snapshots of progress used to determine both; the critical path sequence and amount of delay at the date of each snapshot.

5) As-planned versus as-built windows analysis method: In this retrospective and static (involves manual determination without computer calculations) method the occurrence, impact and causes of each delay are determined by comparing the various schedule sequences to determine the critical path. Then planned dates are compared to actual dates to find delays to completion. This method requires that the analyst is provided access to good quality project information such as methodology, schedule, scope, correspondence and photos in order to gain a high degree of understanding about the project.

In addition to understanding which technique to adopt, the analyst faces a range of complicating factors. Firstly, determining who owns the programme float, the Contractor or the Principal (Critchlow, Farr, Briggs, Hammond, Pickavance \& Lavers, 2005). It may simplistically be assumed that the Contractor does. However, case law has not provided a clear resolution. Furthermore, in the case of a Subcontractor delay, the head Contractor cannot nominate a general float period (Farrow, 2001). Secondly, when a delay occurs which is not on the critical path, whether the Contractor should be entitled to claim the delay as an extension of time because it erodes into their overall project float, or whether only delays to the critical path should be claimed (Winter, 2009). Thirdly, given that the actual level of time management may differ from what is actually required, the delay analyst may not be provided with an accurate critical path programme which has been regularly updated. Certainly, the findings from the $\mathrm{CIOB}$ research reinforce this point. Accordingly, McDonough (2006, p. 6) asserted that in the "... rough and ready world of construction, the documentation and updating of the progress programme is not always dependable. All actual progress information reported in the programme needs to be checked and verified/corrected by detailed reference to the most accurate records available, usually the daily inspection or quality control records." Furthermore if a construction programme is regularly and accurately updated and any issues clearly communicated to all stakeholders and agreed upon, it is unlikely that a dispute will arrive at arbitration in the first place (McDonough, 2006). Finally, the analyst must determine which delay takes precedence in the event of more than one delay occurring concurrently. The issue of concurrent delay is a complicated one with many considerations such as, the conditions of contract used, any difference in causative potency between the different delays, who or what is responsible for each delay and the legal system used in the determination. This discussion highlights a complicated matter which is outside the scope of this paper. (Marrin QC, 2002), provides an informative discussion regarding the correct approach for evaluating Contractors' claims arising out of concurrent delays.

Finnie, D (2012) 'Contract delay what is it and how are we performing?', Australasian Journal of Construction Economics and Building, 12 (1) 83-91 
It is an interesting point that none of the conditions of contract discussed above specify that the construction programme identify a critical path, sequencing of tasks, timing or procedures for updating the programme, or that the baseline programme be jointly accepted between parties. McDonough (2006) identified this issue and asserted that "Contracts can specify, for instance, Critical Path Method (CPM) programming and the monitoring procedures to be adopted by the parties during construction. These can include the joint acceptance of the Baseline Programme; the frequency and accuracy of programme updates; progress measurement and documentation; their analysis of delays, variations and (additional or disputed) claims; and the procedures for the formal revision of the Baseline."

Importantly, there is no stand-alone profession for time management in the construction industry. It is carried out by practitioners whose primary profession is another discipline (Pickavance, 2009). Understanding the process of delay evaluation, its techniques and complications requires a great deal of competency for both current practitioners and for graduates who are likely to participate in time management in the future. This applies both to the analyst and the contract manager. The analyst needs to understand the application of various techniques to the particular case and be aware of the complicating factors. The contract manager not only needs to be capable of producing and updating their programme effectively, but they also need to an understanding of the process for submitting their EOT claims and the associated evaluation in order to know what evidence they will need to provide and whether their claim is likely to succeed from the onset.

\section{How Construction Contracts Distribute Risk Associated with Delay between Parties}

Time has a measurable financial effect on a project (McDonough, 2006). There are different risks associated with contract delays on each party to the construction contract. For the Principal, a delay may represent the risk of a planned investment not providing cash inflows when forecast. This may result in increased short-term funding costs to service the project, or worse still, the risk of missing a market deadline. For example, a developer not having a building ready for student accommodation at the beginning of the academic year, may have to arrange and pay to relocate students into temporary accommodation elsewhere until their building is ready. Worse still, the developer may miss a whole year of rental income which could force them into liquidation. For the Contractor, the risk of a delay usually represents the risk of incurring penalties for completing the project late, such as liquidated damages, and they may be unable to charge this to their Subcontractors. They may also lose credibility within the industry, and incur greater construction costs due to their own increased time-related costs or prolongation costs. Stulic (2010) asserted that commercial risk is allocated in most construction contracts through the following points;

- a specified completion date

- a method to determine when completion has been achieved

- consequences for not achieving the completion date, in the form of liquidated damages

- provision to extend the completion date for extension of time to provide the Contractor with relief against liquidated damages

The distribution of the delay risk between the Contractor and the Principal lies in balancing the enforcement of liquidated damages with the Contractor's claims for prolongation costs. An example of this is where a Contractor's time-related costs are allowed for EOT resulting from variations only, and not for delays caused by such events as inclement weather. So for any delay other than the net effect of a variation, the Contractor becomes exempt from liquidated damages for the delay period, but still incurs their prolongation costs. Conversely, the Principal losses their right to enforce liquidated damages for the time extension, but does not incur costs for the Contractor's prolongation.

One could conclude that liquidated damages are specified to protect the Principal and that the contractual provision of extension of time claims are to protect the Contractor. However extension of time provisions may also protect the Principal. If there were no EOT provisions and the Princi-

Finnie, D (2012) 'Contract delay what is it and how are we performing?', Australasian Journal of Construction Economics and Building, 12 (1) 83-91 
pal (or their agent) delayed the Contractor, the Contractor could claim that the completion date no longer applies and that time is now at large (Lal, 2007; Marrin, 2002). This term is used to indicate that there is no longer an enforceable completion date. In such instance, the Contractor must complete the project within a reasonable time and the Principal can only apply for general damages under common law (Stulic, 2010, p. 2). (Pickavance, Keith, MacLaughlin, Wendy, 2005). This is the basis of the prevention principle, originating from the case of Holmes $v$ Guppy. In which case it was determined that when acts of the Principal prevent the Contractor from achieving the specified completion date, and there is no contractual mechanism to extend the date, the Contractor may be excused from completing the work by the date of completion. The Principal is in a much more vulnerable position with time at large than if there were a new extended completion date. So in effect, EOT contract provisions provide protection to the Principal as well as the Contractor.

\section{Prevention Principal vs Time-bar Clauses}

One debate revolves around whether the specified time-frames or time-bar clauses, take precedence over the prevention principle. Lim (2009) stated that time stipulations in a contract may range from being conditions, in nominate terms or warranties and that a Contractor needs to understand this when they form a contract condition. Their failure to comply would result in a breach of contract. However, it was also recognized that a more liberal approach has been adopted at common law in that "by asking for performance when the promise is guilty of delay is to ask the promisor to do something that he or she never agreed to." (Lim, 2009, p. 5). Jones (2009) determined that the debate between whether the prevention principle or the time-bar clause takes precedence has not yet been resolved and that it is an area which requires further work. He suggested that perhaps the prevention principle should be applied only to reduce the recoverable damages for periods of delay caused by the Principal. However, in his evaluation of case law examples in the UK, Ireland and Australia, Lal (2002) asserted that, on the basis of risk allocation and the requirement of price surety, even when the Principal has caused the delay, the Contractor should not be made exempt from damages unless their claim is in accordance with the conditions of contract. The basis of this argument is that the Principal may not always know that they have caused a delay and that they transfer the risk allocation, including identification and assessment of EOT claims to the Contractor. In addition, EOT claims which are not submitted within the specified time frame may lay dormant and be used as a threat in settlement negotiations. I also agree that time-bar clauses should take precedence on the basis that if the Contractor fails to notify the Principal in a timely manner, the Principal loses the opportunity to pay the Contractor acceleration costs for such things as working overtime, in order to meet the original completion date. Indeed, the acceleration costs may be far less than the costs which the Principal may face if the project is not ready on time, as outlined earlier.

There are a number of ways in which the conditions of contract can affect delay risk between parties, and Head Contractors should be aware of the contract conditions within their Subcontracts, as well as those in the Head Contract.

\section{Timeframes}

Firstly, tighter timeframes imposed on the Contractor to submit EOTs makes claiming more difficult, increasing their risk. NZS3910: 2003 SCC Clause 10.3 allows the Contractor 20 working days to provide notice to the Engineer of an EOT claim or "as soon as practicable thereafter". While NZIA Clause 11.5.2 only allows the Contractor 5 working days, which is the same time allowed for a Subcontractor under Master Builders Clause 10.2.2 b). This raises some issues for the Head Contractor. Given the Subcontractor has the same time period to claim, the Head Contractor has no time to receive and evaluate it against their programme before submitting a claim to the Principal. Also 5 working days may not be adequate for the Contractor to determine whether the delay is genuine or just a minor scheduling problem which may rectify itself (Pinto, 2010). Research conducted by the Chartered Institute of Building (CIOB) indicates that in practice Contractors prefer longer timeframes because they do not want to risk upsetting the Principal early,

Finnie, D (2012) 'Contract delay what is it and how are we performing?', Australasian Journal of Construction Economics and Building, 12 (1) 83-91 
but would rather have more time to try rectifying the delay in order to save face, even at their own cost.

\section{Preconditions for Claiming EOT}

Secondly, the Contractor's risk may be increased by allowing fewer pre-conditions for claiming. NZIA SCC-2005: Clause 11.5.1 provides a list of such pre-conditions, for example "(f) weather that interferes with the progress of the work". To acknowledge the difficulty with foreseeing every possible event, clause (I) provides for "Something else of significance beyond the Contractor's control". In a similar manner NZS 3910: 2003: Clause 10.3.1 lists reasons for an extension of time claim and also provide (f) "Any circumstances not reasonably foreseeable by an experienced Contractor at the time of tendering and not due to the fault of the Contractor". One advantage of NZS 3910: 2003 is where Clause 10.3.7 clarifies that "The Contractor shall not be entitled to compensation for time related Costs where an extension of time is granted on grounds other than the net effect of a Variation" while NZIA SCC leaves this area open to interpretation. Master Builders SCC 2009 Section 10.2 provides that Subcontractors are entitled to an EOT for any reason described in the Head Contract. The maximum extension is that of which the Contractor is entitled to under the Head Contract or for delay caused by suspension of the Contract Works. Clause 10.2.1 b) also provides the inclusion of any delays caused by the Principal, Engineer or Contractor or other Subcontractors and, interestingly, "for any other act of prevention of the Contractor not specifically covered in this clause". Dependant on the Head Contract conditions, there is a risk to the Head Contractor that "any other act" implies something outside of their Head Contract. The subcontractor is tied into the Head Contractor's programme in Section 10.9 by providing that the Subcontractor must "complete their works as required by the Contractor's current construction programme (which has been issued to the Subcontractor). This ensures that there is no delay to the progress and completion of the Head Contract Works". Again Clause 10.3.1 provides that "the Subcontractor is not entitled to compensation for costs incurred in relation to the extension, unless the extension was a variation..."

\section{Opportunities for Further Research}

One limitation within this essay is that the research about time management skill levels was conducted overseas. Therefore, there exists an opportunity to carry out similar research within New Zealand. When attempting to source data measuring the success of construction projects in New Zealand with regard to timing, it was found that two KPI benchmarking initiatives had failed or were struggling, due to lack of industry participation. Constructing Excellence in New Zealand and the NZ Centre for Advanced Engineering (CAENZ) had both attempted such benchmarking initiatives over the past decade. This not only means there is a lack of information to determine industry performance in such areas as time management, but also represents a missed opportunity for well managed construction companies to gain objective data, which they could use to market their company and also apply to highlight areas requiring attention.

Another limitation is that while three different contract conditions were analysed, different procurement methods were not. One area of potential research would be to compare different procurement methods such as lump sum, cost reimbursement or collaborative partnership contracts to determine the effects on delay management.

\section{Recommendations for Improvement}

In order to simplify the contractual requirements for time managers and contract administrators following changes are recommended:

Firstly, NZIA and NZS3910 work together to produce a common set of contract clauses relating to the timing and evaluation of EOT claims. It is recommend that "or reasonable time thereafter" be removed from timing and instead be replaced with a fixed duration. This would clarify the clause and help to focus practitioners' attention to it. This may also help in clarifying any dispute between the prevention principle and the time-bar clause in the case of a dispute. A period of say, 10 work-

Finnie, D (2012) 'Contract delay what is it and how are we performing?', Australasian Journal of Construction Economics and Building, 12 (1) 83-91 
ing days would provide the Contractor with one week to identify the delay and one week to claim it. If the Contractor is updating their programme weekly, this should be achievable. Alternatively a further two days could be potentially added for float.

Secondly, NZIA, NZS3910, and NZMBF SCC compile a common list of acceptable preconditions. This will not only provide consistency across the Head Contract conditions, but will also remove the Head Contractors of having different requirements for claiming delays under their head contract to that of their Subcontractors claiming delays to them.

Thirdly, NZIA and NZS3910 revise their conditions of contract to include provision for specifically requiring the construction programme to identify the critical path, task sequencing and requirements for updating the programme.

Furthermore the skill level of time management and contract administration throughout industry needs to be improved. This may be achieved by implementing training to up-skill current practitioners. There may exist opportunity for training providers to develop short courses specific to this area.

In addition, educational institutions of diploma and/ or degree courses, in the field of construction and project management, should review their graduate profiles to ensure that graduates entering the workforce have sufficient skills. For example, we can look at two of the courses which form part of the New Zealand National Diplomas in both Quantity Surveying and Construction Management. These are Unit Standards 9637 Programming and 9661 Administration of Contracts. Programming requires updating construction programmes to account for contingency events and re-scheduling resources and tasks accordingly, but makes no mention of recording and using this information for the purpose of submitting EOT claims. Only Contract Administration requires students to understand the process of EOT claims. It would be easy for education providers to miss the important linkage between the time management contained in Programming and the contractual process of EOT in Contract Administration, especially given that the two subjects are likely taught at different times by different lecturers.

\section{Conclusion}

There is a linkage between the skill levels required to manage project timing and the use of those skills to identify and claim for contract delays. There are common law requirements for practitioners to be aware of such as the prevention principle versus time-bar clauses. One benefit of upholding the time-bar clause is that it protects the Principal's opportunity to pay acceleration costs. Additionally practitioners must be aware of the requirements for claiming delays under the conditions of contract specific to that project. Furthermore, differences exist between New Zealand conditions of contract NZIA, NZS3910 and NZ Master Builder's Conditions of Contract, mainly in the area of timing clauses and the listed criterion for claiming extensions of time. Moreover, none of the contract conditions reviewed, specify that the construction programme be produced to identify a critical path and sequencing of tasks. Finally, it is important for training institutions to ensure that their training programmes encompass the relationship between time management and contract delay. This should include competencies for effective time management and understanding the various techniques for delay evaluation and the associated complicating factors.

\section{References}

Constructing Excellence in New Zealand. (Retrieved April 1, 2011). www.constructing.co.nz.

Barry, D. (2009). Beware the Dark Arts! Delay Analysis and the Problems with Reliance on Technology. Society of Construction Law, 1-14.

Dr Critchlow, Julian; Farr, Alastair; Briggs, Steve; Hammond, John; Pickavance, Keith; Professor Lavers, Anthony. (2005). The Great Delay Analysis Debate. Society of Construction Law.

Farrow, T. (2001). Delay Analysis - Methodoly and Mythology. Society of Construction Law.

Lal, H. (2002). Extension of Time: The Conflict Between The "Prevention Principle and Notice Requirements as a Condition Precedent. Society of Construction Law. 
Lal, H. (2007). The Rise and Rise of Time-bar Clauses for Contractors' Claims: Issues for Construction Arbitrators. Society of Construction Law.

Lim, T. (2009). Essence of Time in Construction Contracts. The Australasian Journal of Construction Economics and Building, 1-6.

Marrin QC, J. (2002). Concurrent Delay. Society of Construction Law.

McDonough, F. (2006). Analysing and Handling Delays. Constructing NZ, 7.

McDonough, F. (October 2006). Analysing and Handling Delays in. Constructing NZ, 6-7.

Nash, S. C. (2002). Delay and Disruption: Legal Considerations. Society of Construction Law.

New Zeland Centre for Advanced Engineering (CAENZ). (Retrieved April 1, 2011). www.caenz.com.

Pickavance, K. (2001). Principles and Policies in Delay Analysis. Society of Construction Law.

Pickavance, K. (2009). Managing the Risk of Delayed Completion in the 21st Century: The CIOB Research. Society of Construction Law.

Pickavance, Keith; MacLaughlin, Wendy. (2005). A Little of Time at Large: Proof of a Reasonable Time to Complete in the Absence of a Completion Date. Society of Construction Law.

Pinto, J. K. (2010). Project Management Achieving Competitive Advantage 2nd Edition. New Jersey: Pearson Education.

Professor Jones, D. (2009). Can Prevention Be Cured By Time Bars? Society of Construction Law.

Stulic, M. (2010). Prevention and the Allocation of the Risk of Project Delays: Evolution or Revolution? Society of Construction Law.

The Society of Construction Law. (October, 2002). Delay and Disruption Protocol. Available from www.eotprotocol.com.

Winter, J. (2009). How Should Delay Be Analysed - Dominant Cause and its Relevance to Concurrent Delay. Society of Construction Law. 